ECCOMAS

Proceedia
COMPDYN 2019

$7^{\text {th }}$ ECCOMAS Thematic Conference on Computational Methods in Structural Dynamics and Earthquake Engineering M. Papadrakakis, M. Fragiadakis (eds.) Crete, Greece, 24-26 June 2019

\title{
A NEW SEISMIC ISOLATION DEVICE BASED ON TRIBOLOGICAL SMOOTH ROCKING (TROCKSISD)
}

\author{
Maurizio Froli ${ }^{1}$, Linda Giresini ${ }^{2}$, and Francesco Laccone ${ }^{3}$ \\ ${ }^{1}$ Department of Energy, Systems, Territory and Construction Engineering, University of Pisa, \\ Largo L. Lazzarino, 56122, Pisa (Italy) \\ m.froli@ing.unipi.it \\ ${ }^{2}$ Department of Energy, Systems, Territory and Construction Engineering, University of Pisa \\ Largo L. Lazzarino, 56122, Pisa (Italy) \\ linda.giresini@unipi.it \\ ${ }^{3}$ Institute of Information Science and Technologies (ISTI) “A. Faedo" \\ National Research Council of Italy (CNR), \\ via G. Moruzzi 1, 56124, Pisa (Italy); \\ Department of Energy, Systems, Territory and Construction Engineering, University of Pisa, \\ Largo L. Lazzarino, 56122, Pisa (Italy) \\ francesco.laccone@isti.cnr.it
}

\begin{abstract}
In the field of seismic risk mitigation of art objects, an innovative isolation device is here illustrated. The device, called TROCKSISD (Tribological ROCKing Seismic ISolation Device), couples multiple components to dissipate energy and control smooth rocking: spherical contact surfaces with frictional layers, elastic springs ensuring re-centering and viscous elastic dampers. The conceptual idea is described and the equations of motions of the two degrees of freedom system presented, discussing the performance-based structural behaviour and the mechanical/geometric parameters involved. Moreover, dynamic analyses are performed to understand the role of the frictional layers with respect to the peripheral dampers in the mitigation of motion under spectrum compatible seismic records. The results in terms of rocking spectra are presented and comparisons with the equivalent single degree of freedom system without the isolation device are made.
\end{abstract}

Keywords: Damage Avoidance Design, Rocking, Seismic protection, Seismic isolation, Vibration control, Friction. 


\section{INTRODUCTION}

A classical approach in earthquake engineering invokes the performance-based Capacity Design for which the formation of plastic hinges is necessary to dissipate energy provided by the ground motion. Despite human lives and goods are preserved with this approach, high and medium-high return period events cause damages not only on secondary components but also on primary structural members. Moreover, repair costs are usually as high as rebuilding costs and, in the immediate post-event time, the reconstruction can be unsafe and sometimes useless. Damage Avoidance Design (DAD) and other isolation techniques were therefore proposed as alternative design paradigms in earthquake engineering. DAD design philosophy was set out by Mander and Cheng [1] and later applied for practical cases of braced frame structures [2], among others. However, this concept was not completely new at that time, neither in the theoretical research nor into building practice. Following the early Housner's work [3], related to a non-smooth contact problem, efforts were spent on studying the rocking motion of rigid blocks; Meek [4] introduced the coupled effect of flexibility of the bracing with rocking of foundation, and Aslam et al. [5] the effect of pre-stressing. On the other hand, frictional problems were treated in rigid block limit analysis of masonry structures [6,7], based on specific formulations of 3D yield conditions for contact interfaces [8]. Friction sliding connections and rocking resisting systems may be found in ancient Greek and Roman temples or in Japanese Pagodas [9], and this is probably why some of these buildings survived so long, not sensitively damaged by earthquakes. More recent examples of DAD structures are the $315 \mathrm{~m}$ span South Rangitikei Bridge [10] and the $35 \mathrm{~m}$ high tower of Christchurch [11]. Other examples are the Alan Macdiarmid Building at Victoria University in Wellington and Southern Cross Endoscopy Building in Christchurch [12], both located in New Zealand. DAD structures follow the principles of isolation, with absence of damage and energy dissipation, and give the possibility of controlling displacements, to respect specific limit states. These characteristics are based on the rocking behavior, whose analytical framework was extensively investigated in the past. When discussing about rocking, it is necessary to distinguish between rigid contact problems - where the base of the rocking element can be considered rigid - and elastic contact models - where the base exhibits elasticity. For the first typology, rocking is able to describe the seismic behavior of rigid structural elements such as, for instance, masonry walls in out-of-plane modes. Diverse contributions were provided for analyzing the rocking response of walls in free configuration [13,14] or for horizontally [15-18] or vertically [19] restrained walls. For masonry structures the assumption of rigid blocks is generally acceptable, but for other materials, several authors included the elasticity of the superstructure in the formulation [20-23]. In addition, the dynamics of an elastic structure coupled with a rocking wall was analyzed by [19]. In the context of elastic contact models, Psycharis and Jenning [24] firstly proposed the rocking rigid block on an elastic foundation realized through coupled springs and dampers. These models were recently used, properly updated, for new isolation techniques for instance to protect marble structures [25], showing that these devices are highly performant to sustain seismic actions. However, still only few contributions are available to quantify the base isolation properties allowed by free rocking [26,27], which is the core of the DAD philosophy. In this framework of elastic contact models, the present paper proposes an innovative device, conceived by M. Froli, able to protect from damages different types of superstructures by following the DAD principles. In general, the device allows a favorable dynamic behavior since:

(i) in case of low-intensity excitation, the superstructure remains undamaged, so that the post-event serviceability is preserved; 
(ii) in case of a strong excitation, the motion of the superstructure is mitigated by a frictional contact and the effect of dampers, enabling the structure to smoothly rock.

The use of this device aims at limiting the damage of slender structures and valuable objects under seismic actions and vibrations. The acronym of this device has been inspired by its mechanics: TROCKSISD (Tribological ROCKing Seismic ISolation Device). The concept and the equations of motions are obtained for the corresponding two degrees of freedom (2DOF) system (Section 2), whereas the main design steps are discussed in Section 3 to size geometrically and mechanically the device in a performance-based perspective. Afterwards, a quantitative estimation of the response of the system is obtained by performing nonlinear dynamic analyses (Section 4), and finally a parametric analysis is carried out to estimate the influence of friction on the global behavior of the dynamic system (Section 5).

\section{TRIBOLOGICAL ROCKING SEISMIC ISOLATION DEVICE - TROCKSISD}

\subsection{Inspiring idea}

For structures or historic assets that are slender and vulnerable to impacts, tensile stresses and vibrations, bending, induced by dynamic motion, is a relevant problem. The present concept introduces, as an alternative to common shear or pendulum devices, a novel isolation and dissipation system based on smooth rocking of the structure. This idea brought to a jointed connection that is installed between the structure and the foundation and works as an articulated mechanism. The TROCKSISD is made of two ribbed plates: the upper one that is integral with the superstructure, the lower with the foundation. Two homothetic and frictionally connected spherical cups are included between these ribbed plates and respectively jointed to them. The two surfaces can reciprocally slide once the static friction is overcome, allowing a smooth rocking of the structure. Aiming at conferring additional damping and stiffness as well as re-centering capability, the outer perimeters of the ribbed plates are equipped with viscous-elastic dampers. A mock up showing the conceptual idea is shown in Figure 1.

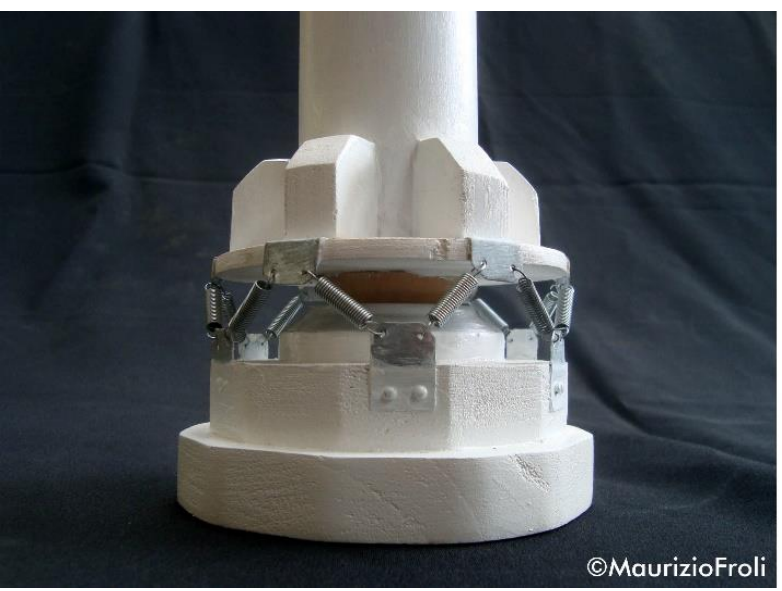

(a)



(b)

Figure 1 TROCKSISD mock-up: (a) rocking prevented in stick phase, (b) rocking admitted in sliding phase.

\subsection{Performance-based structural behavior}

The presence of friction at the interface of the two spherical cups allowing to distinguish and appropriate design two mechanic regimes. A fist one identifies the stick phase, in which 
the jointed mechanism is blocked because the external excitation is not able to exceed the static friction. In this stage the structure reacts elastically. A second regimes identifies the slip phase, in which the rocking is activated with smooth oscillations.

This double regime well fits a performance-based design. The geometric and mechanic parameters of the device can be sized to have the stick phase at the SLS (Serviceability Limit State), while the sliding phase at ULS (Ultimate Limit State). In this latter case, attention should be paid to design the components not to be accidentally in contact. Moreover, displacement demands should be guaranteed as well as equilibrium and stability to the structure. A beneficial energy dissipation occurs at the ULS thanks to friction and viscosity of dampers.

\subsection{Conceptual design and parameters}

The design of TROCKSISD should contemporarily meet several geometric and structural requirements: it should be resistant to vertical and shear forces, while it should allow the dynamics of the jointed mechanism for bending moments. The device is consequently made of four main components, with reference to Figure 2: the upper ribbed plate, the convex spherical cup, the concave spherical cup and the dampers.

The upper ribbed plate is integral with the structure to protect and is connected to the convex spherical cup, which is bolted to the ribs of the upper plate. The latter transfers both vertical and horizontal loading to the lower components, while allowing the rotation around the pole $\mathrm{O}$. The friction develops by contact of the two spherical cups onto a surface with radius $\mathrm{R}$, cut at a latitude angle of $\varphi_{0}$. To guarantee a constant surface in contact the convex cup is larger and is cut at a latitude angle of $\bar{\varphi}$. The concave spherical cup is integral with the lower plate, which represents the component in contact with the foundation.

Viscous-elastic link the perimeter of the upper plate and the perimeter of the lower plate, and add stiffness (k), damping (c), and re-centering capacity to the system. Dampers that result polar-arrayed and each couple of them is arranged as a V bracing to help the system to self-center and to oppose torsional effects. The hexagon is a convenient shape for the plates, where for each edge a couple of dampers can be installed. A 3D view of the device is reported in Figure 3.

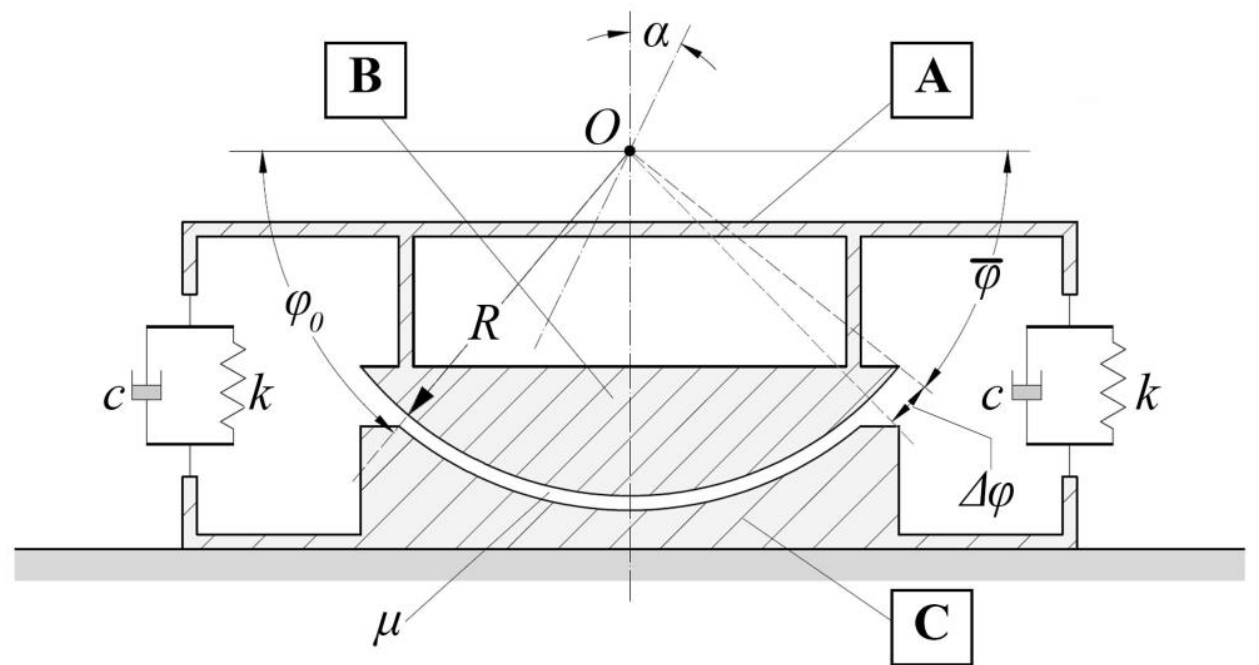

Figure 2 Section of TROCKSISD: geometric and mechanical parameters. 


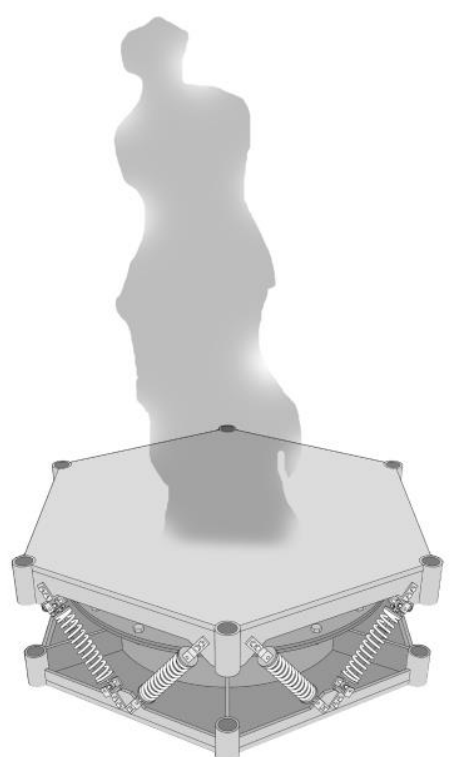

(a)

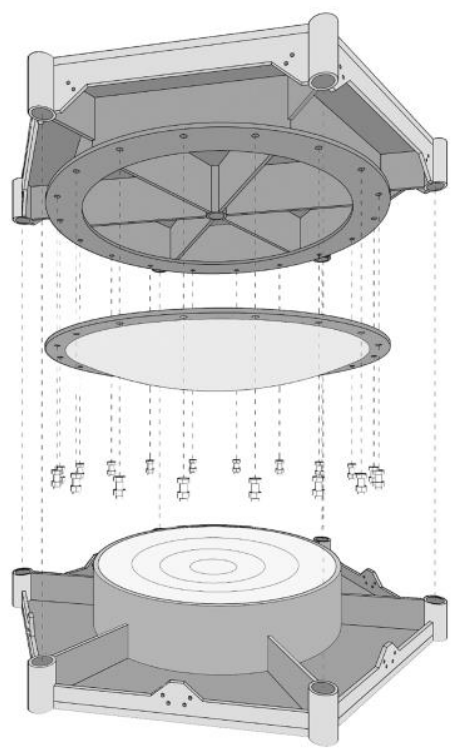

(b)

Figure 3 TROCKSISD 3D view: (a) axonometric view; (b) exploded view.

The material for TROCKSISD is common steel for all its component parts. Moreover, the interface of the two spherical cups can be equipped with stainless steel, anodized aluminum or PTFE on the basis of the desired friction coefficient.

\section{ANALYTICAL MODEL}

An analytical model of the planar behavior of the TROCKSISD is developed by adopting a 2DOF simplification, in which the structure is a translational mass and the device is a rotational mass with reference to Figure 4.

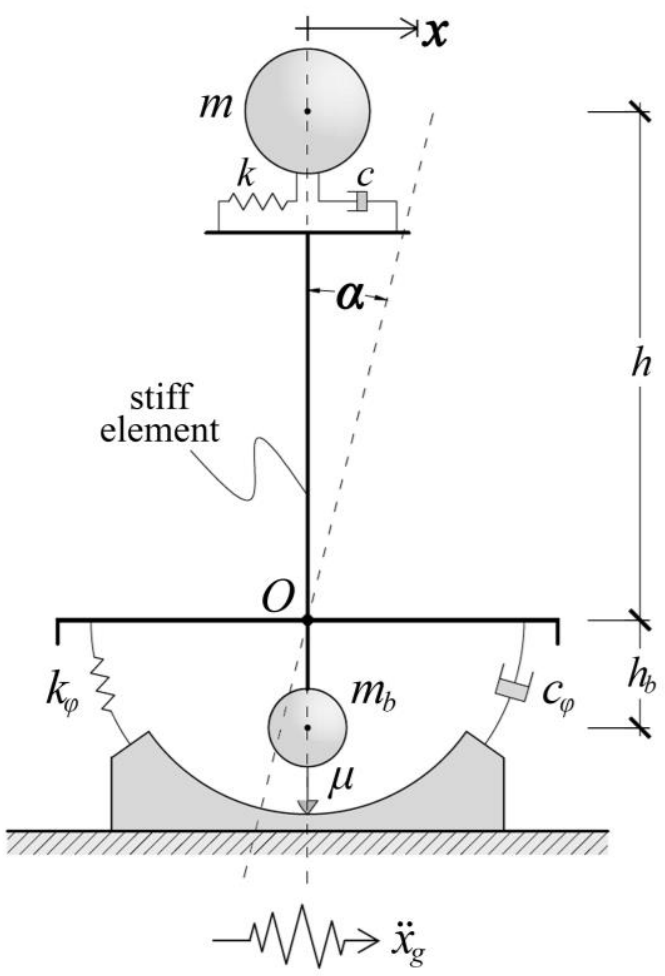

Figure 4 Schematic view of the 2DOF model. 
The friction contribution in the dynamics of the system is expressed by means of the tribological moment that is generated by rotations $\alpha$ of the device. This frictional reaction depends on the friction coefficient $\mu$ and the radial pressures on the spherical cup.

The tribological moment expresses the dependency on $\varphi$ and R as per Eq. (1)

$$
\mathrm{M}_{\mu}=\mu \operatorname{PR} \Phi\left(\varphi_{0}\right)
$$

If all parameters are considered lumped the equation of the dynamic equilibrium can be expressed as:

$$
\left\{\begin{array}{c}
\mathrm{m} \ddot{\mathrm{X}}+\mathrm{c} \dot{\mathrm{x}}-\operatorname{ch} \dot{\alpha}+\mathrm{kx}-\mathrm{kh} \alpha=\bar{F} \\
I_{\mathrm{b}} \ddot{\alpha}+\left(\mathrm{c}_{\alpha}+c h^{2}\right) \dot{\alpha}+\left(\mathrm{k}_{\alpha}+\mathrm{k} h^{2}\right) \alpha-\operatorname{ch} \dot{\mathrm{x}}-k h x+\mathrm{M}_{\mu}=\bar{M}
\end{array}\right.
$$

The structure is described by the stiffness $\mathrm{k}$ and the damping $\mathrm{c}$, while the device is described by the friction coefficient $\mu$ the stiffness $\mathrm{k}_{\alpha}$ and the damping $\mathrm{c}_{\alpha}$. In the dynamic motion, the three phases may occur:

- A static phase characterized by absence of motion, so where both the velocity and the angular acceleration equal zero:

- The incipient motion phase, where the velocity is still null, but the static friction is exceeded;

- The dynamic phase, with nonzero velocity.

The geometric and mechanical parameters can be selected based on target displacement and action as per the Eurocodes Limit States.

\section{DYNAMIC ANALYSIS AND RESULTS}

The To highlight the performances of the TROCKSISD, an ideal case study is selected and analysed. Seismic loading is expressed by means of response spectrum compatible accelerograms obtained from the site specifications. Natural response spectrum compatible accelerograms are generated by the software REXEL v3.5 [30] on the basis of two target spectra, one for the SLS and one for the ULS. Seven accelerograms that provide a mean spectrum close to the code design response spectrum (within the upper limit of $+30 \%$ and lower limit of $-10 \%$ ) are selected for both cases.

The site is in Castelnuovo di Garfagnana, Italy $\left(44^{\circ} 07^{\prime} 19^{\prime \prime} \mathrm{N} 10^{\circ} 24^{\prime} 20^{\prime \prime} \mathrm{E}\right)$. The site class is B. The structure parameters are: height $H=3.50 \mathrm{~m}$; the mass $m=1500 \mathrm{~kg}$, the period is $T=0.357 \mathrm{~s}$, while mechanical parameters $k=466 \mathrm{kN} / \mathrm{m}$ and $\xi=0.01$. The spherical cup is sized to have the rocking mechanism locked at the SLS, so when the mass $m$ is submitted to the plateau acceleration the structure should mechanism should behave as stick. The resulting parameters are $R=1685 \mathrm{~mm}$ and $\varphi_{0}=72^{\circ}$.

The mechanical parameters of dampers can be derived from the ULS spectra, using as target maximum rotation the value of $\alpha_{\max }=3.5^{\circ}$ and supposing to have steel/steel frictional contact. The values of $\mathrm{k}_{\varphi}=200 \mathrm{kNm}$ and $\xi_{\varphi}=0.08$ are obtained. Thus, from the modal analysis the first period of the system results $\mathrm{T}_{1}=1.4 \mathrm{~s}$, so that the seismic force demand is lowered, while at the meantime the displacement demand can be met by the components.

The role friction is to regulate the rocking mechanism and to provide for energy dissipation. The effect of limiting the rotations can be visualized by means of the results of a parametric analysis, in which the friction is suppressed (on $\mu=0.00$ ) while $\xi_{\varphi}$ is varied to match the curve with steel/steel friction $\mu_{\mathrm{s}}=0.18\left(\mu_{\mathrm{d}}=0.09\right)$ and $\xi_{\varphi}=0.08$. The displacement spectra of absolute maximum rotations $\alpha_{\max }$ is reported in Figure 4.

The curves exhibit some peaks due to resonance phenomena, which flatten whether damping increases. With respect to the reference curve $\left(\mu_{s}=0.18 ; \xi_{\varphi}=0.08\right)$, the absolute maximum 


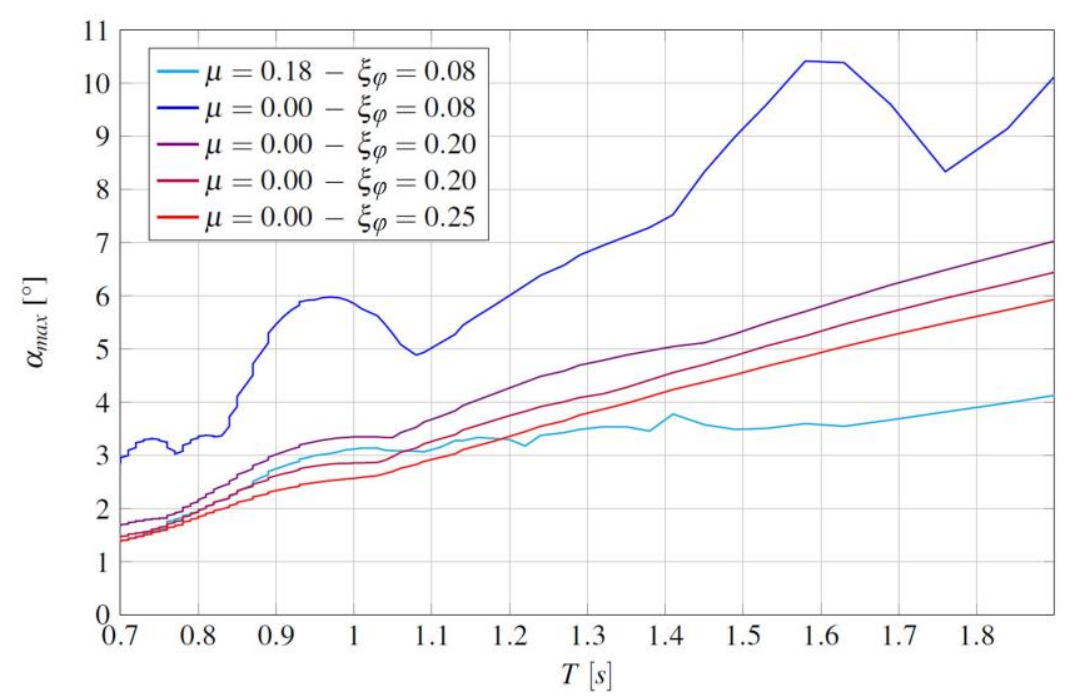

Figure 4 Displacement spectra of the absolute maximum rotation $\alpha_{\max }$ for several values of the rotational damping ratio $\xi_{\varphi}$ in the period range $\mathrm{T}_{1}=0.7-1.9 \mathrm{~s}$ with and without friction.

rotations are magnified along the entire monitored spectrum if the friction is suppressed and dampers with same characteristics are adopted. Increasing the damping ratio, for values of periods smaller than $10 \mathrm{~s}$ the curves tend to approach the reference curve. For larger periods the curves diverge, and, while the reference curve tends to be constant, the frictionless curves are monotonically growing. To guarantee performances which are similar to those of a tribological device at least for lower periods, the viscous damping capacity should increase substantially, bringing to larger devices that may also impair the feasibility of the device. Consequently, the contribution of friction is fundamental both in the dynamic behaviour to minimize the displacement and to increase the economy of the device.

In Figure 6 and Figure 5 are reported the results of the dynamic analyses respectively at the SLS and at the ULS for some significant natural accelerogram the displacement time history. Both DOFs are reported.

At the SLS, friction substantially prevents the sliding of the base surfaces, namely the second DOF $\alpha$ of the system is blocked. However, sometimes the rocking mechanism is activated because of localized peaks in the accelerograms (as in the case of S1). The possible residual rotation is even small (maximum value $\alpha_{\mathrm{r}}=0.08$; mean value $\overline{\alpha_{\mathrm{r}}}=0.03$ ). Also, from the S1 output the re-centering capability of the system is evident. Concerning the first DOF, the horizontal displacement does not exceed the value of $11 \mathrm{~mm}$ for which the superstructure is designed to behave elastically.
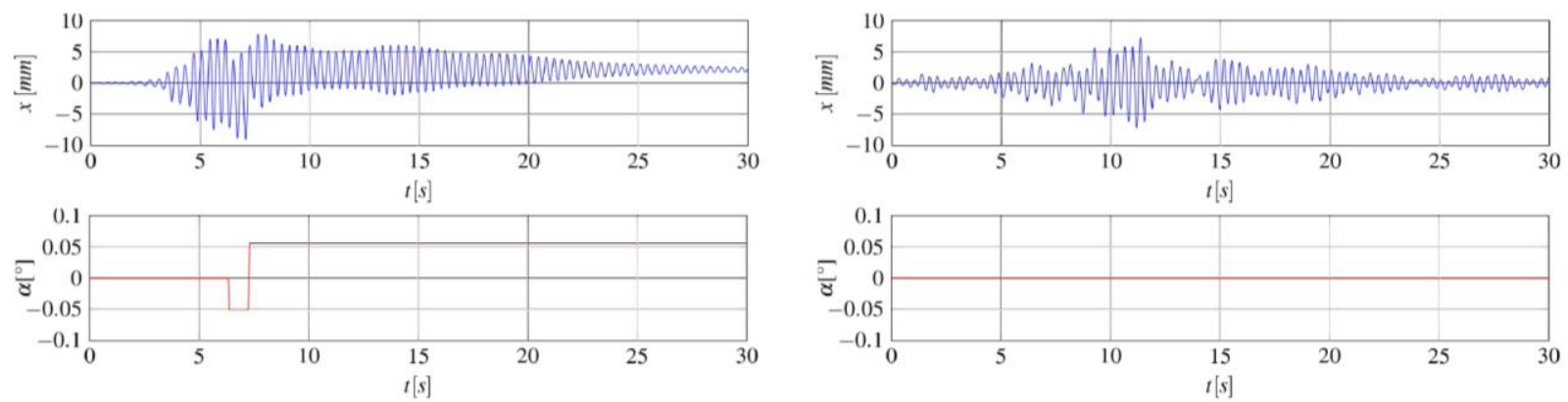

Figure 6 SLS dynamic response for S1 and S3 seismic records (in blue the horizontal displacement time-history, in red the rotation time-history). 

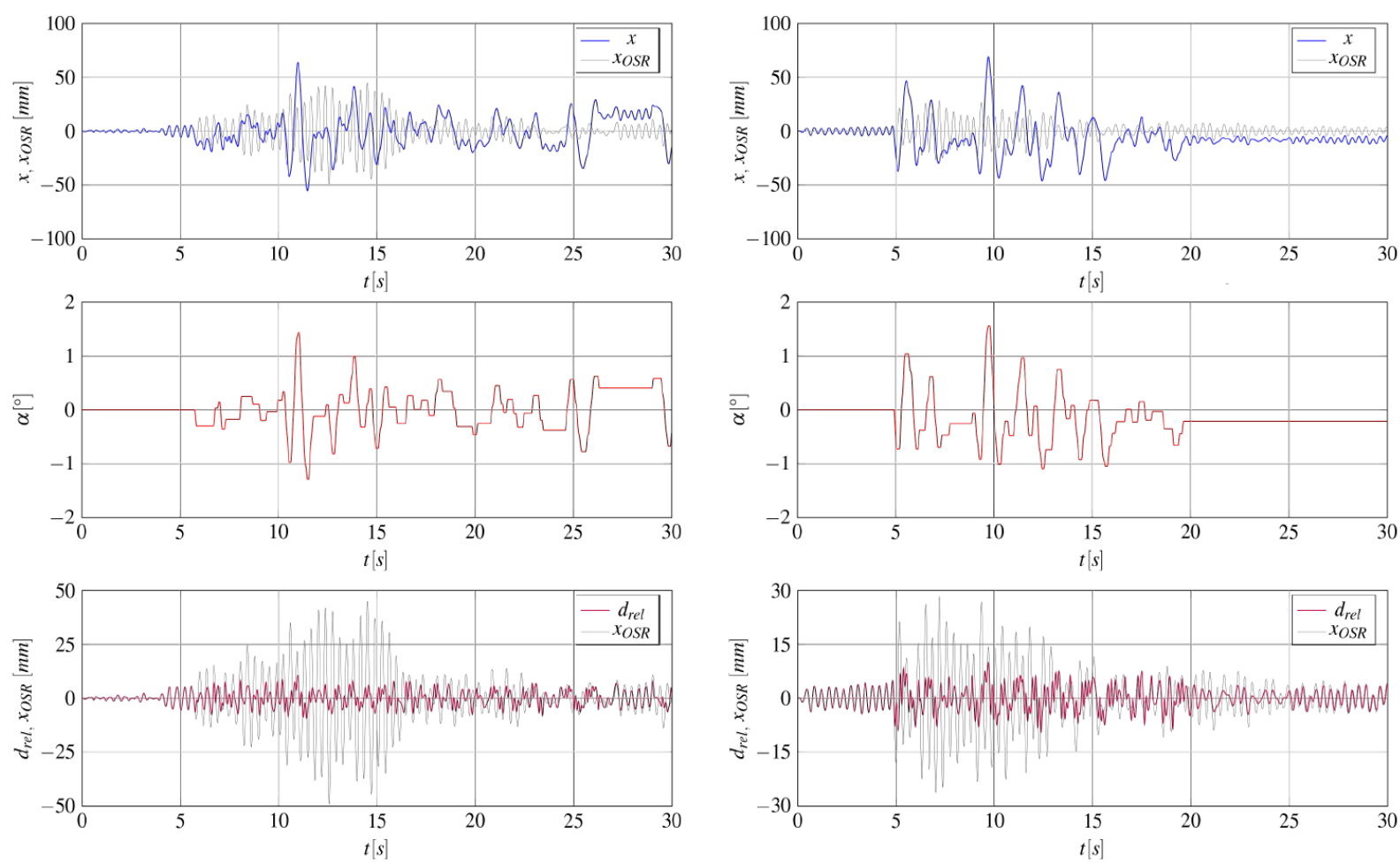

Figure 7 ULS dynamic response for S4 and S6 seismic inputs.

The dynamic response at the ULS for S4 and S6 seismic record is shown in Figure 7. To effectively evaluate the response of the present system, the results concerning the first DOF are compared with the results of the reference SDOF oscillator (OSR).

In the first plot, the absolute horizontal displacement of both systems is shown. As expected for any isolated system, the structure equipped with TROCKSISD exhibits larger displacement than the reference SDOF oscillator.

The second plot concerns the oscillations of the rotational DOF, where slip-stick motions with incipient motion phases included occur. Moreover, there are residual rotations at the end of each acceleration story. Their magnitudes, as in the SLS case, are relatively reduced, if compared with the maximum rotations.

In the third plot the SDOF oscillator curve is compared with the relative displacement of the superstructure mass $x_{\mathrm{rel}}$, where the horizontal displacement due to rotations at the second DOF is deducted from the absolute value.

In all cases, the rotation values are close to the limitation imposed in the design phase of $3.5^{\circ}$ for the absolute maximum. Concerning the translation of the first DOF, $\mathrm{x}_{\max }$ values are meanly three times larger than these of the reference SDOF oscillator in terms of absolute values, or at least more than two times larger for the mean value ( $38 \mathrm{~mm}$ vs. $90 \mathrm{~mm}$ ). This result is a consequence of shifting the $\mathrm{T}_{1}$ period towards higher values in order to obtain reduced level of accelerations but paying with increased displacement. Nevertheless, it is interesting to observe that the relative displacement is about the $30 \%$ of the SDOF oscillator. This result means that using TROCKSISD produces displacement $\mathrm{x}_{\mathrm{rel}}$ that are smaller than those for the SDOF oscillator. Consequently, the structure is less stressed. 


\section{CONCLUSIONS AND FUTURE DEVELOPMENTS}

The Tribological ROCKing Seismic ISolation Device (TROCKSISD) can provide seismic protection of slender structures and valuable objects such as artistic or historic assets (altars, statues, art objects, etc.). It is based on the development of friction at the interface of a jointed mechanism that allows smooth rocking of the superstructure in a frictional model. Viscouselastic dampers provide for additional stiffness and damping as well as re-centering capability. Two main regimes in the dynamic behavior occur: a prevalent stick phase (at SLS) and of mixed slip-stick phase (at ULS).

The behavior of a system equipped with such a device has been described by means of a simple 2DOFs analytical model with all lumped parameters. From the analyses results, it can be stated that TROCKSISD follows DAD principles because the structure substantially remains in the elastic phase in both the SLS and the ULS. Moreover, the residual rotations at ULS are very small and shall be reversed once the excitation stops, providing for post-event serviceability.

\section{ACKNOWLEDGEMENTS}

The authors would like to acknowledge Ing. Enrique Vagelli Saldana Vila for the development of the MATLAB codes and the drawing of figures.

\section{REFERENCES}

[1] Mander JB, Cheng CT. Seismic resistance of bridge piers based on damage avoidance design 1997.

[2] Pollino M. Seismic design for enhanced building performance using rocking steel braced frames. Engineering Structures 2015. DOI: 10.1016/j.engstruct.2014.11.005.

[3] Housner GW. The behavior of inverted pendulum structures during earthquakes. Bulletin of the Seismological Society of America 1963; 53(2): 403-417. DOI: 10.1017/CBO9781107415324.004.

[4] Meek JW. Dynamic response of tipping core buildings. Earthquake Engineering \& Structural Dynamics 1978. DOI: 10.1002/eqe.4290060503.

[5] Aslam M, Godden WG, Scalise DT. Earthquake Rocking Response of Rigid Bodies. Journal of the Structural Division 1980; 106(2): 377-392.

[6] C. Casapulla; L. U. Argiento. In-plane frictional resistances in dry block masonry walls and rocking-sliding failure modes revisited and experimentally validated. Composites Part B: Engineering 2018; 132: 197-213. DOI: 10.1016/j.compositesb.2017.09.013.

[7] Casapulla, C., Giresini, L., Sassu, M., Lourenço PB. Rocking and kinematic approaches of masonry walls: state of the art and recent developments. Buildings 2017. DOI: 10.3390/buildings7030069.

[8] Casapulla C, Maione A. Formulating the torsion strength of dry-stacked stone blocks by comparing convex and concave contact formulations and experimental results. Indian Journal of Science and Technology 2016; 9(46): 107346. DOI: 10.17485/ijst/2016/v9i46/107346. 
[9] Hanazato T, Nagai T, Yanagisawa K, Hidaka K, Sakamoto I, Watabe M. Greek temple and timber Pagoda in Japan-comparison of the aseismic structural performances. WIT Transactions on The Built Environment 1970; 42.

[10] Beck JL, Skinner RI. Seismic Response of a Reinforced Concrete Bridge Pier Designed to Step. Earthquake Engineering and Structural Dynamics 1974. DOI: 10.1002/eqe.4290020405.

[11] Sharpe RD, Skinner RI. The seismic design of an industrial chimney with rocking base. Bulletin of the New Zealand National Society for Earthquake Engineering 1983; 16(2): 98-106.

[12] Priestley MJN, Sritharan S (Sri), Conley JR, Stefano Pampanin S. Preliminary Results and Conclusions From the PRESSS Five-Story Precast Concrete Test Building. PCI Journal 1999. DOI: 10.15554/pcij.11011999.42.67.

[13] Sorrentino L, D'Ayala D, de Felice G, Griffith MC, Lagomarsino S, Magenes G. Review of Out-of-Plane Seismic Assessment Techniques Applied To Existing Masonry Buildings. International Journal of Architectural Heritage 2017; 11(1): 2-21. DOI: 10.1080/15583058.2016.1237586.

[14] Casapulla C. MA. Critical Response of Free-Standing Rocking Blocks to the Intense Phase of an Earthquake. International Review of Civil Engineering 2017; 8(1): 1-10.

[15] Giresini L. Design Strategy For The Rocking Stability Of Horizontally Restrained Masonry Walls. 6th ECCOMAS Thematic Conference on Computational Methods in Structural Dynamics and Earthquake Engineering M. Papadrakakis, M. Fragiadakis (eds.) Rhodes Island, Greece, 15-17 June 2017, 2017.

[16] Giresini L, Fragiacomo M, Lourenço PB. Comparison between rocking analysis and kinematic analysis for the dynamic out-of-plane behavior of masonry walls. Earthquake Engineering and Structural Dynamics 2015; 44(13): 2359-2376. DOI: 10.1002/eqe.2592.

[17] Giresini L, Sassu M. Horizontally restrained rocking blocks: evaluation of the role of boundary conditions with static and dynamic approaches. Bulletin of Earthquake Engineering 2017; 15(1): 385-410. DOI: 10.1007/s10518-016-9967-7.

[18] Giresini L, Fragiacomo M, Sassu M. Rocking analysis of masonry walls interacting with roofs. Engineering Structures 2016; 116: 107-120.

[19] Makris N, Vassiliou MF. Dynamics of the Rocking Frame with Vertical Restrainers. Journal of Structural Engineering 2015; 141(10).

[20] Oliveto G, Caliò I, Greco A. Large displacement behaviour of a structural model with foundation uplift under impulsive and earthquake excitations. Earthquake Engineering and Structural Dynamics 2003. DOI: 10.1002/eqe.229.

[21] Acikgoz S, Dejong MJ. The interaction of elasticity and rocking in flexible structures allowed to uplift. Earthquake Engineering and Structural Dynamics 2012. DOI: 10.1002/eqe.2181.

[22] Caliò I, Greco A. Large displacement behavior of a rocking flexible structure under harmonic excitation. JVC/Journal of Vibration and Control 2016. DOI: $10.1177 / 1077546314537862$. 
[23] Muto K, Umemura H, Sonobe Y. Study of the overturning vibrations of slender structures. Proceedings of the 2nd World Conference on Earthquake Engineering. Tokyo, Japan, vol. 2, 1960.

[24] Psycharis IN, Jenning PC. Rocking of slender rigid bodies allowed to uplift. Earthquake Engineering \& Structural Dynamics 1983; 11: 57-76.

[25] Baggio S, Berto L, Favaretto T, Saetta A, Vitaliani R. Seismic isolation technique of marble sculptures at the Accademia Gallery in Florence: numerical calibration and simulation modelling. Bulletin of Earthquake Engineering 2015; 13(9): 2719-2744. DOI: 10.1007/s 10518-015-9741-2.

[26] Meek JW. Effects of Foundation Tipping on Dynamic Response. Journal of Structural Division 1975.

[27] Huckelbridge AA, Clough RW. Seismic response of uplifting building frame. Journal of the Structural Division 1978; 104(8): 1211-1229.

[28] Worden K, Tomlinson GR. NONLINEARITY IN STRUCTURAL DYNAMICS. Detection, Identification and Modelling. Physics 2001: 670. DOI: 10.1887/0750303565.

[29] Clough RW, Penzien J. Dynamics of Structures. 2013. DOI: 10.1002/9781118599792.

[30] Iervolino I, Galasso C, Cosenza E. REXEL: Computer aided record selection for codebased seismic structural analysis. Bulletin of Earthquake Engineering 2010. DOI: 10.1007/s10518-009-9146-1. 